\title{
Intonation of 'now' in resolving scope ambiguity in English and Dutch
}

\author{
Bettina Braun $^{\mathrm{a}, \mathrm{b}, *}$, Aoju Chen ${ }^{\mathrm{b}}$ \\ ${ }^{a}$ Department of Linguistics, University of Konstanz, Universitätsstr. 10, Fach 186, 78467 Konstanz, Germany \\ ${ }^{\mathrm{b}}$ Max Planck Institute for Psycholinguistics, Nijmegen, Netherlands
}

\section{Introduction}

Ambiguity is inherent in the use of language. A common type of ambiguity arises from the different ways in which words can be grouped into larger chunks. As a consequence, the same string of words can have different interpretations. For instance, the sentence The teacher said John was intelligent might convey that either John or the teacher was intelligent. In spoken language, prosody - in particular phrasing - provides a useful cue to resolve such ambiguities (e.g., Price, Ostendorf, Shattuck-Hufnagel, \& Fong, 1991; Snedeker \& Trueswell, 2002; Speer, Kjelgaard, \& Dobroth, 1996). In the example above, a break after said conveys that John was intelligent, but a break before and after said John conveys that the teacher was intelligent.

Ambiguities can also arise when the meaning of a certain word can apply to different parts in a sentence (i.e., scope ambiguity), as in the case of focus particles such as even, only, and also. The exhaustive particle only, for instance, can refer to Bill - Bill being the only person introduced to Mary (1a), to Mary - Bill being only introduced to one person, namely Mary (1b), or to both Bill and Mary - John only introduced two people to each other, namely Bill to Mary (1c). Prosody is again effective in resolving these ambiguities. Speakers can specify the intended interpretation of the utterance by assigning a falling accent to the constituent(s) that fall in the scope of only - marked by squared brackets under (1) (hereafter we refer to accent placement and accent type

\footnotetext{
* Corresponding author at: Department of Linguistics, University of Konstanz Universitätsstr. 10, Fach 186, 78467 Konstanz, Germany. Tel.: +497531 882386.

E-mail address: bettina.braun@uni-konstanz.de (B. Braun).
}

generally as intonation). Furthermore, $1 \mathrm{a}$ and $1 \mathrm{~b}$ can be differentiated by means of phrasing, inserting an intonational phrase boundary after Bill or not. The intonation of a particle itself can also play a role in scope marking, as in the case of German auch ('also') (e.g., Krifka, 1991; Reis \& Rosengren, 1997).

(1) a. John only introduced [Bill] to Mary.

b. John only introduced Bill [to Mary].

c. John only introduced [Bill] [to Mary].

Scope ambiguity induced by focus particles has received abundant attention in the literature, in terms of formalization (e.g., Altman, 1976; Bayer, 1996; Büring \& Hartmann, 2001; König, 1994; Rooth, 1992), processing in adults and children (e.g., Crain, Ni, \& Conway, 1994; Paterson, Liversedeg, White, Filik, \& Jaz, 2006; Berger, Müller, Höhle, \& Weissenborn, 2007), and second language acquisition (Dimroth \& Watorek, 2000). Much less is known about scope ambiguities caused by the adverb now.

Now may have three functions (e.g., Halliday \& Hassan, 1976; Hirschberg \& Litman, 1993; Shiffrin, 1987). It can be used as a temporal adverb, indicating that an event is taking place or should take place at the time when the utterance is produced as in Let's discuss that now! (Bartsch, 1972). Further, it can be used as a discourse marker (or 'cue phrase' in Hirschberg \& Litman's terms) and signal the introduction of a new subtopic. Finally, now can signal a temporal sequence (e.g., He already did $A$ and now he does $B$ ), and parallels the past tense sequential adverb then (e.g., He first $\operatorname{did} A$ and then he did B). Hirschberg and Litman (1993) showed that the first two functions can be differentiated intonationally. They analyzed productions from a radio call-in 
program and reported differences in phrasing and pitch accent realization for the temporal and discourse usage. In its temporal usage, now appeared mostly at the end of intermediate phrases and was usually accented. In its discourse usage, now was mostly positioned phrase-initially and left unaccented.

In this study, we focus on the usage of now as a sequential adverb. More specifically, we investigate how speakers vary the prosodic realization of now to signal the scope of the upcoming contrasts in game instructions as in (2). These kinds of instructions (especially $2 \mathrm{~b}$ and $2 \mathrm{c}$ ) are frequently used in psycholinguistic experiments investigating the role of accent placement and accent type in online reference resolution (e.g., Chen, den Os, \& de Ruiter, 2007; Dahan, Tanenhaus, \& Chambers, 2002).

(2) a. Put the zebra in cell 1; now put [the baby] in cell 1. (ObjectContrast)

b. Put the zebra in cell 1; now put the zebra [in cell 2]. (LOCATIONCONTRAst)

c. Put the zebra in cell 1; now put [the baby] [in cell 2]. (DOUBleContRAsT)

Irrespective of the locus and number of contrasts, now needs to be placed phrase-initially in English. Therefore, English speakers are likely to vary prosody (phrasing and intonation) of now to disambiguate the locus and number of contrasts. Indeed, an initial indication for such uses of intonation can be found in the experimental materials of the above-mentioned psycholinguistic studies. In Dahan et al.'s (2002) American English materials, now was spoken with an $\mathrm{H}^{*}$ pitch accent when the object was contrastive (2c) but mostly with a rising accent (either $\mathrm{L}^{*}+\mathrm{H}$ or $\mathrm{L}+\mathrm{H}^{*}$ ) when the object was maintained (2b). In the study by Chen et al. (2007) on British English, now was mostly unaccented or realized with a weak rise when the object was contrastive (2c) but with a strong rise when the object was maintained (2b). These production data (though produced only by a single speaker each) suggest that the intonation of now varies depending on the information status of the upcoming object. However, in the stimuli of both studies, a contrastive object was always moved to a new location (resulting in a double contrast as in example $2 c$ ). Therefore, it remains to be tested whether the observed patterns hold for more than one speaker and whether speakers also vary the prosodic realization of now to differentiate a contrast in the object from a double contrast.

Secondly, this study investigates whether underlying word order flexibility affects the use of prosody in this regard. Previous studies on the linguistic markings of information structure have shown that speakers not only employ prosody but also word order and particles (Keller \& Alexopoulou, 2001 for Greek; Kim \& Avelino, 2003 for Mexican Spanish; Göbbel, 2003 for Romanian, Zubizarreta, 1998 for Germanic and Romance languages in general; Vallduví \& Engdahl, 1996 for German, Dutch, English, Catalan, Hungarian and Turkish; Swerts \& van Wijk, 2005 for Dutch). Therefore, prosody might not be used at all (or to a lesser extent) if a language allows speakers to disambiguate the contrast conditions by means of word order. A language parexcellence to test this assumption is Dutch. Dutch has a very similar intonational grammar as English (Gussenhoven, 1988; 't Hart, Collier, \& Cohen, 1990) and the same intonational flexibility (e.g., Ladd, 1996; Vallduví \& Engdahl, 1996). More importantly, informal inquiries suggest that at least the locus of the contrast (ObjectContrast vs. LocationContrast) can be disambiguated by means of word order: $n u$ ('now') can optionally be placed prior to the contrasted constituent (as shown in example (3)).

(3) a. Verplaats de zebra naar vak 1; verplaats nu [de baby] naar vak 1.

lit: Put the zebra in cell 1; put now the baby in cell 1. b. Verplaats de zebra naar vak 1 ; verplaats de zebra nu [naar vak 2].

lit: Put the zebra in cell 1; put the zebra now in cell 2.

c. Verplaats de zebra naar vak 1 ; verplaats $n u$ [de baby] [naar vak 2].

lit: Put the zebra in cell 1; put now the baby in cell 2 .

The structure of the paper is as follows: in Section 2 we shall report data from a web experiment to corroborate the claim that English has more rigid word order constraints in these instructions than Dutch. In Sections 3 and 4, we will present data on the prosodic realization of this sequential adverb in English and Dutch.

\section{Word order preferences in English and Dutch}

English and Dutch participants were presented with instruction pairs similar to those in example (3) and rated the acceptability of the second instruction.

\subsection{Methods}

\subsubsection{Materials}

Eighteen pairs of instructions were constructed for Dutch and English each. The position of the adverb in the second instruction (phrase-initial, after the verb, and after the object) and contrast condition (LocationContrast, ObjectContrast, and DoubleContrast) were varied orthogonally. Object nouns were highly frequent, every-day words. Half of them were monosyllabic, half disyllabic.

\subsubsection{Participants}

Twenty-eight native English and thirty native Dutch speakers participated in the experiment. English participants were made aware of the web experiment through personal networks in London and Chicago. Nineteen were from the US and 9 from the UK. The Dutch participants were recruited via the subject pool from the Max Planck Institute for Psycholinguistics in Nijmegen (MPI). All participants (28 female, 30 male) were between 19 and 46 years old. Participants could freely decide where to perform the web experiment.

\subsubsection{Procedure}

Two lists were constructed; the presentation of the stimuli was pseudo-randomized. Two subsequent trials differed in at least one factor (adverb position or contrast condition). Participants received instructions that the experimental sentences were written by a non-native speaker for a board game in which objects had to be moved to different positions. They were told that the non-native speaker was not allowed to use pronominalized forms and that their task was to rate the acceptability of the second instruction on a scale from 1 (not acceptable) to 5 (highly acceptable). After they had entered their rating via the keyboard of their PC, the next sentence pair appeared. The experiment lasted approximately $5 \mathrm{~min}$.

\subsection{Results}

One Dutch participant and one English participant who took less than $90 \mathrm{~s}$ overall (less than $5 \mathrm{~s}$ per trial) and one Dutch participant who took more than $15 \mathrm{~min}$ overall were excluded as outliers. Ratings were analyzed using multi-level regression models with adverb position, contrast condition, and language as fixed factors and participant as a random factor (Pinheiro \& Bates, 2002; Baayen, 2008). Data points for which the absolute standardized residuals were greater than 2.5 were removed as outliers and the model was refitted. $p$-Values were estimated as posterior probabilities based on a Markov Chain Monte Carlo simulation with 10,000 runs. 
Results showed a three-way interaction between adverb position, contrast condition, and language $(p<0.0001)$. In what follows we first present the results from English participants, followed by those from Dutch participants.

For English participants, there were main effects of contrast condition $(p<0.05)$ and adverb position $(p<0.0001)$, but no interaction $(p>0.1)$. To ensure that the interaction term does not improve the fit of the model, we compared the predictive power of the full model with the one without the interaction term. The loglikelihood ratio for the simpler model was 566.1, compared to 563.2 for the model with the interaction $\left(\chi^{2}(4)=5.9, p>0.2\right)$. This supports the interpretation that there is no interaction between the factors. Ratings for trials with a LocATIONCONTRAST were rated less acceptable than trials with a DoubleContrast $(\beta=-0.2$, Lower Bound $=-0.36$, Upper Bound $=-0.04, p<0.05$ ). More importantly, positioning the adverb phrase-initially was perceived as more acceptable (mean rating 4.7 ) than positioning the adverb after the object (mean rating 3.0, $p<0.0001$ ), which in turn was perceived as more acceptable than placing it after the verb (mean rating 2.4, $p<0.0001$ ), see Fig. 1.

For Dutch participants, there were main effects of adverb position $(p<0.0001)$, contrast condition $(p<0.0001)$, and an interaction between the two $(p<0.0001)$, see Fig. 2. Overall, $n u$ in phrase-initial position was considered worst, independent of contrast condition (mean rating 2.1 compared to 4.2 for positioning the adverb after the verb, $p<0.0001$ and 4.0 for positioning it after the object, $p<0.0001$ ). Dutch listeners judged sentences as most acceptable if $n u$ was positioned after the verb but more so when there was a contrast in the location or a double contrast and less so when there was a contrast in the object. In addition, placing $n u$ after the object received highest ratings in OBJECTCONTRAST (mean rating 4.4, $p<0.05$ ) and lowest in LocationContrast (mean rating 3.1, $p<0.01$ ).

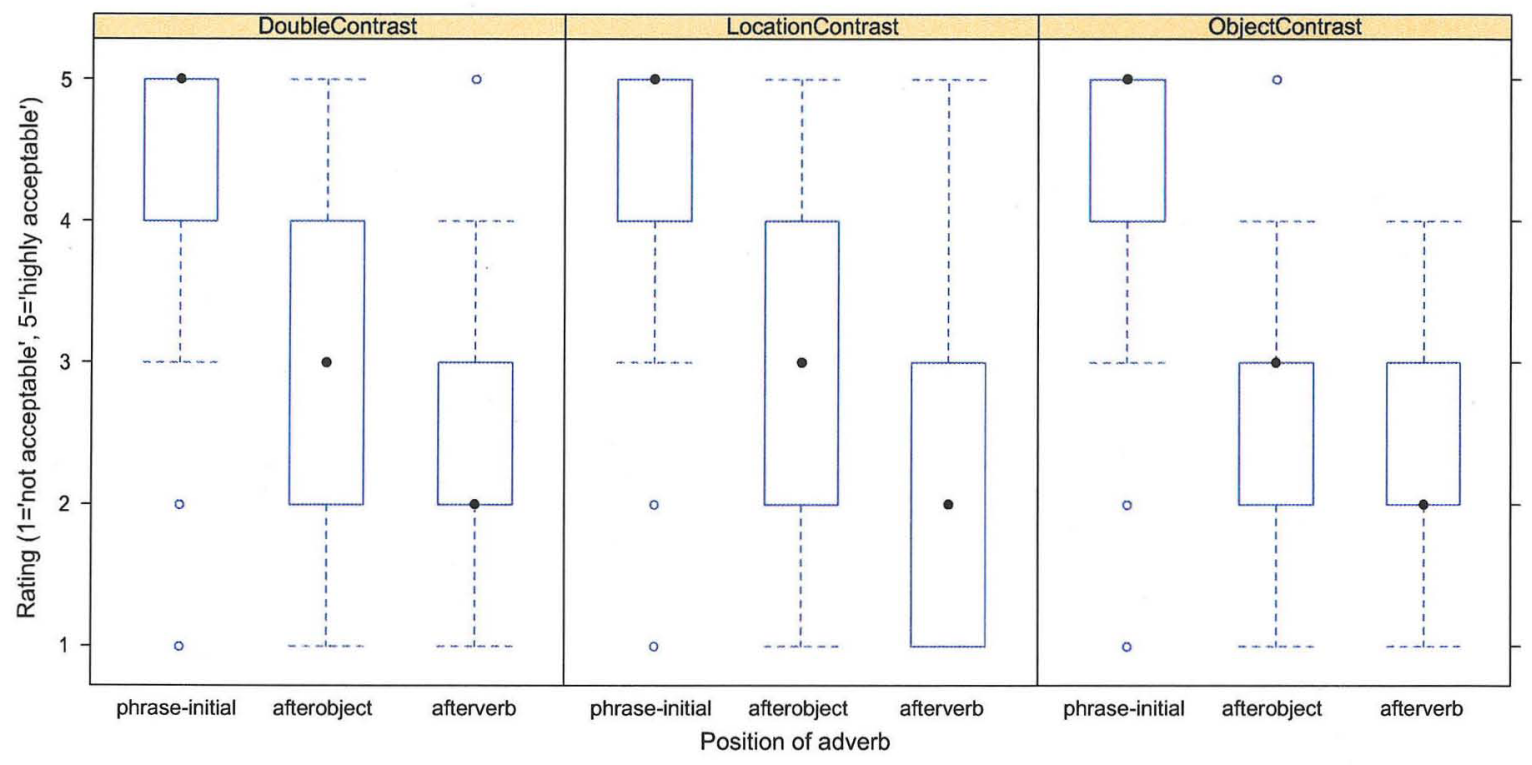

Fig. 1. Box-plot showing the ratings of the English participants.

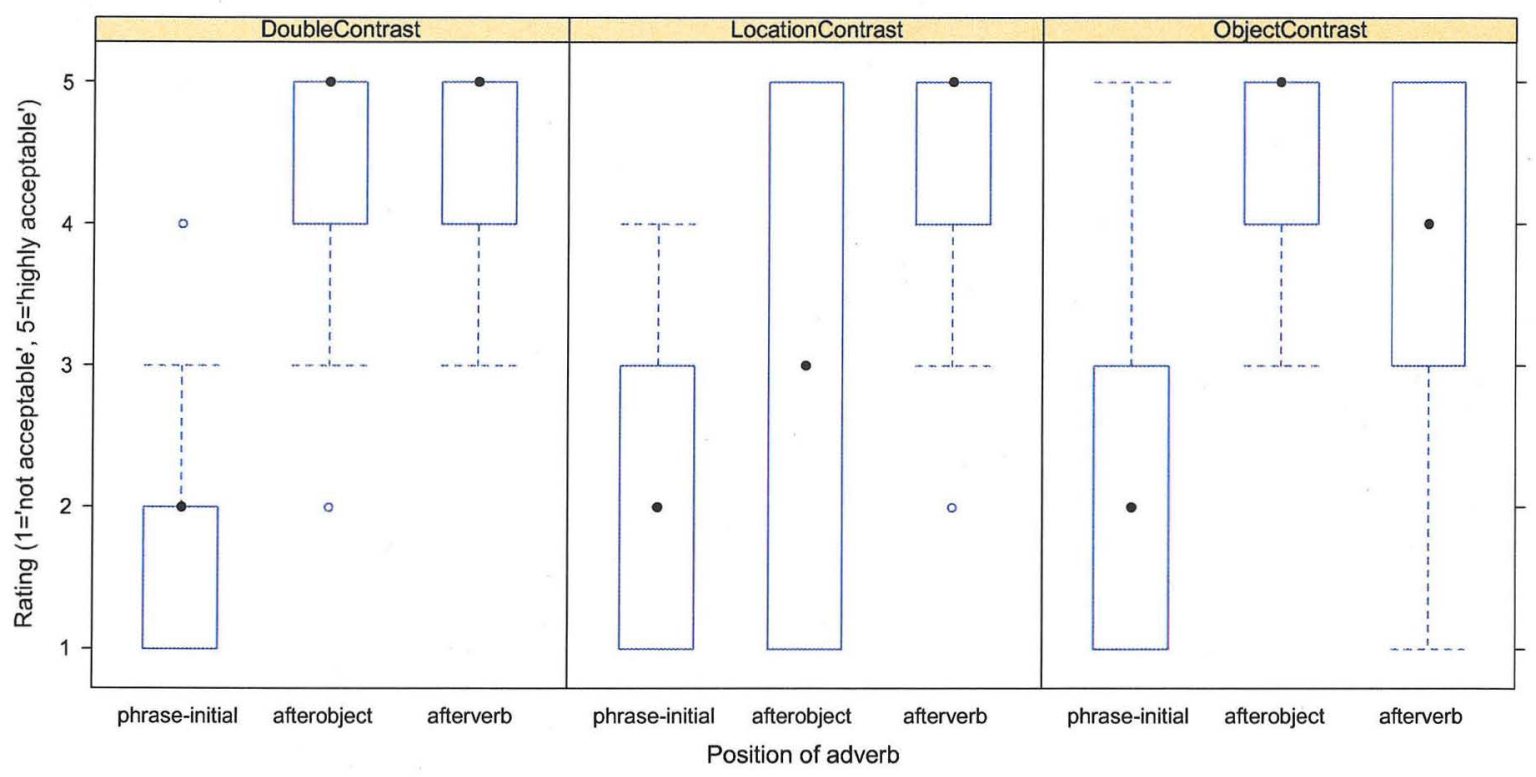

Fig. 2. Box-plot showing the ratings of the Dutch participants. 


\subsection{Discussion}

Rating data from the web experiment showed that English is indeed more restricted in word order than Dutch when it comes to positioning the adverb now/nu (hereafter Now when we refer to it language-independently). English participants preferred sentences in which now was placed sentence-initially, independent of contrast condition. Dutch participants' preference, on the other hand, was dependent on contrast condition. In sentences with a contrast in location, they preferred nu after the verb, but in ObjectContrast and DoubleContrast sentences, they judged $n u$ after the object as more acceptable. The fact that these results differ from our initial impressions shows that there is more than one way to mark upcoming contrasts in Dutch. Possibly, participants' preference is dependent on the prosodic structure projected during reading (e.g., Fodor, 2002) and on the willingness to tolerate unexpected productions by a non-native speaker of Dutch. But importantly, these experiments have provided evidence that English and Dutch differ with respect to constraints on word order for the adverb now.

\section{English production experiment}

A movie clip description task (cf. Speer, Warren, \& Schafer, 2003; Swerts, 2007; Terken \& Hirschberg, 1994) was used to elicit sentences like the examples in (2). Participants watched 15 movie clips depicting two objects on a $3 \times 3$ grid that were moved to different locations. Their task was to describe the action they saw in the form of an instruction to someone else after the action was completed.

\subsection{Methods}

\subsubsection{Materials}

Twelve pairs of familiar objects were selected. For every object pair, three movie clips were constructed, resulting in 36 movie clips in total. Each movie clip consisted of two parts. Initially, the screen depicted a green $3 \times 3$ grid $(1345 \times 1030$ pixels $)$ with nine cells. Each cell contained the respective cell number in black Arial $12 \mathrm{pt}$ in the top left corner, highlighted with pink background color. The grid contained two objects (white line drawings on black background, $96 \times 96$ pixels each) which were placed together in one of the cells (a black-white drawing of the display is shown in Fig. 3). In the first part of the movie clip, one of the two objects was moved to another cell. For the second part of the movie clip there were three possibilities. In ObjectContrast, the other object was moved to the same location as the first object was moved to. In LocationConTRAST, the same object was moved again but to another location. In DoubleContrast, the other object was moved to another empty cell. For each object pair, the object moved in the second part of the movie clips was identical across conditions.
The movie clips were created using FinalCut Pro and exported as a self-contained movie to a QuickTime file (DV PAL $48 \mathrm{kHz}$ ). The first movement started $200 \mathrm{~ms}$ after the display of the grid containing the objects and took $3 \mathrm{~s}$. This was followed by a pause of $4 \mathrm{~s}$ in which participants could phrase the first instruction. The second movement also took $3 \mathrm{~s}$ and was followed by a 4-s pause so that participants had time to phrase the second instruction.

\subsubsection{Participants}

Eighteen Southern British English speakers (9 female and 9 male) took part in the experiment. Sixteen of them were students at the University of Sussex; two were exchange students who just arrived in Nijmegen at the time of testing. Participants were unaware of the purpose of the experiment and received a small fee for their participation.

\subsubsection{Procedure}

Participants were seated in front of a computer screen. They were informed that they were about to see a number of movie clips consisting of two parts and that they should describe the actions they saw in the form of an instruction to another person so that he/she could perform the respective actions. Therefore, participants were asked to speak clearly and at a normal speaking rate. In addition, they were instructed to refer to the object by its name (the first word that came to their mind) and to refer to the cell by using the number printed in the cell (1-9). Participants were also told to use the word put for describing the action, the word now to mark the second instruction, and to avoid the word also.

Three experimental lists were compiled, each containing 12 movie clips, four in each condition. The three lists together contained all the object pairs in all conditions. To familiarize participants with the task, each list started with three practice movie clips, one in each condition. In this practice session, participants were corrected if they did not follow the experimenter's instructions.

The experiment was conducted by means of the NESU (Nijmegen Experiment Setup) experimental software. Sixteen participants were tested individually in a quiet room at the University of Sussex. The remaining two were tested in a sound-attenuated booth at the MPI. Twelve pairs of instructions were elicited from each participant. The productions were recorded on DAT-tapes with a sampling rate of $48 \mathrm{kHz}$ and a resolution of 16-bit.

\subsection{Analysis}

The second sentence in each pair of instructions was marked on the word level for the verb (put), the adverb (now), the target object to be moved, and the location (cell $n$ or just the number). In what follows, we will refer to the instruction containing the adverb as 'second instruction'. The second instructions were all produced in the order Now put the $X$ into cell $Y$.
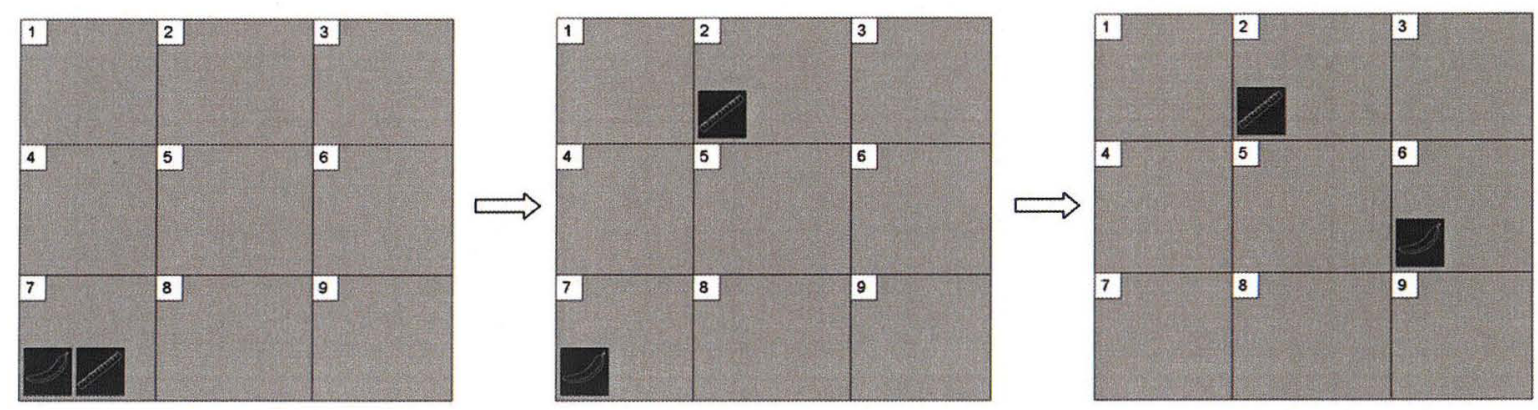

Fig. 3. Example displays of a DoubleContrast video clip in grayscale. Left panel shows the initial configuration, middle panel shows the display after the first action, right panel shows the configuration after the second action. 

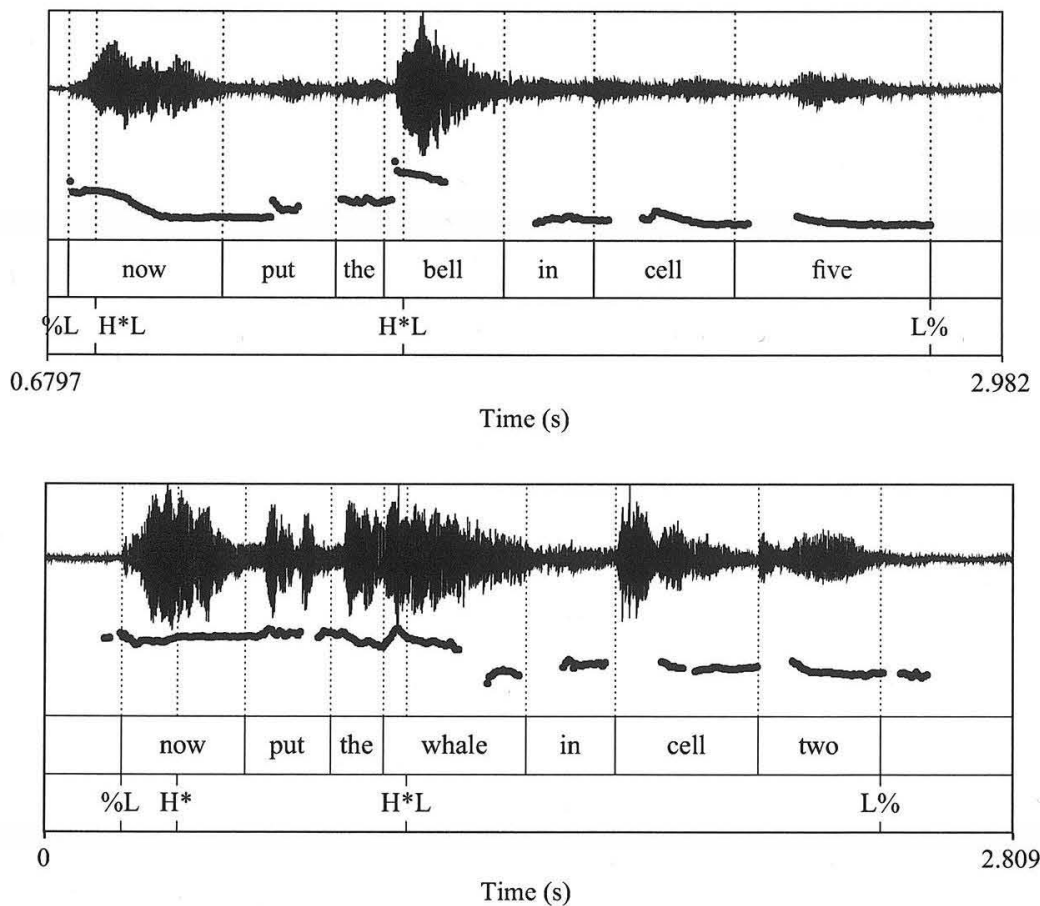

Fig. 4. Pitch tracks of two example utterances in OBjEcrContrast produced by an English speaker.

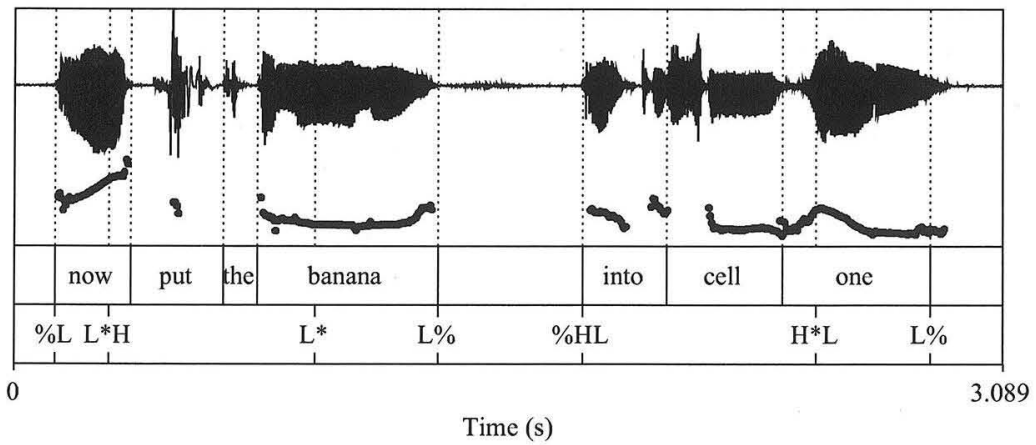

Fig. 5. Pitch track of an utterance in LocationContrast produced by an English speaker.

To ease subsequent prosodic analysis, we focused on the productions from the female speakers. ${ }^{1}$ One speaker had to be excluded because of poor recording quality, leaving 8 speakers for the analysis. Five utterances from these speakers had to be discarded because of hesitations and absence of the adverb. Following this selection procedure, 89 second instructions were analyzed further. There were 32 utterances in LOCATIONCONTRAST, 29 in ObjectContrast, and 28 in DoubleContrast.

To ensure that speakers appropriately encoded the intended information structures, we subsequently recruited five native speakers of English (students at the University of York) to evaluate the information structure in the 89 second instructions. These judges indicated for each of these second instructions whether they expected the preceding first instruction, which was not presented to them, to differ in the object, the location, or both. The presentation of utterances was blocked by speaker and the utterances were randomized within a speaker. The judges were

\footnotetext{
${ }^{1}$ Impressionistic analysis suggests similar patterns for the male participants. But their productions showed a smaller f0-range and were therefore harder to analyse than the female participants' productions.
}

blind to contrast condition. Utterances were classified correctly by the majority of the judges (three or more) in $85.9 \%$ of the cases. The small number of misclassifications was restricted to interpreting the intended object or location contrast as a double contrast.

\subsubsection{Phonological analysis}

The 89 second instructions were prosodically annotated following IViE (Grabe, 2004), a notation system proposed for varieties of British English that originated from ToDI (Transcription of Dutch Intonation, see Gussenhoven, 2005). In IViE, only differences in the tonal movement on and following the stressed syllable (i.e., 'trailing tones') and the tonal movement at intonational phrase boundaries (corresponding to break index 4 in the ToBI system) are transcribed. The sentences were first annotated by the authors independently and blind to contrast condition. Then, the labels were compared and doubtful cases as well as disagreements ( $<10 \%$ of the cases) were resolved by the authors together. Three accent types occurred in now, $\left(\mathrm{H}^{*}-\right.$ high level, $\mathrm{H}^{*} \mathrm{~L}-$ fall, and $\mathrm{L}^{*} \mathrm{H}-$ low rise, for a schematic representation of these accent types see Table A1 in the Appendix).

Example pitch tracks of English utterances are shown in Figs. 4 and 5 . 


\subsubsection{Phonetic analysis}

To further corroborate the phonological analysis of now which was relatively difficult due to its shortness and the consequent compression in the realization of the tonal targets (Grabe, 1998) - we analyzed the realizations of now phonetically. Since now is fully sonorant, the fundamental frequency contour of the adverb was extracted automatically at $5 \mathrm{~ms}$ steps using Praat (Boersma \& Weenink, 2009). The first five f0-values (from the first $20 \mathrm{~ms}$ in now) were not considered because of potential f0-perturbations. The f0-maximum in the adverb was identified automatically. The f0-excursion of the rise was calculated from the first available f0-value of the adverb to the f0-maximum in the adverb and was converted to semitones. The f0-excursion of the fall was calculated from the f0-maximum in the adverb to the fo-value at the mid-point of the following syllable ('put') and converted to semitones. The mid-point of the following syllable was used because the adverb itself was too short to determine a fall in some cases and the mid-point of the following syllable could be reliably extracted. Furthermore, the alignment of the f0-maximum with respect to the onset of now was measured. Finally, we calculated the relative duration of the adverb (duration of the adverb divided by the duration of the verb). This normalization was done to minimize effects due to different speech rates. The complete set of alignment, scaling and duration information is summarized in Table A2 in the Appendix.

All these acoustic variables were subjected to individual multi-level regression models with accent type as a fixed factor $\left(\mathrm{H}^{*}, \mathrm{H}^{*} \mathrm{~L}, \mathrm{~L}^{*} \mathrm{H}\right)$, and

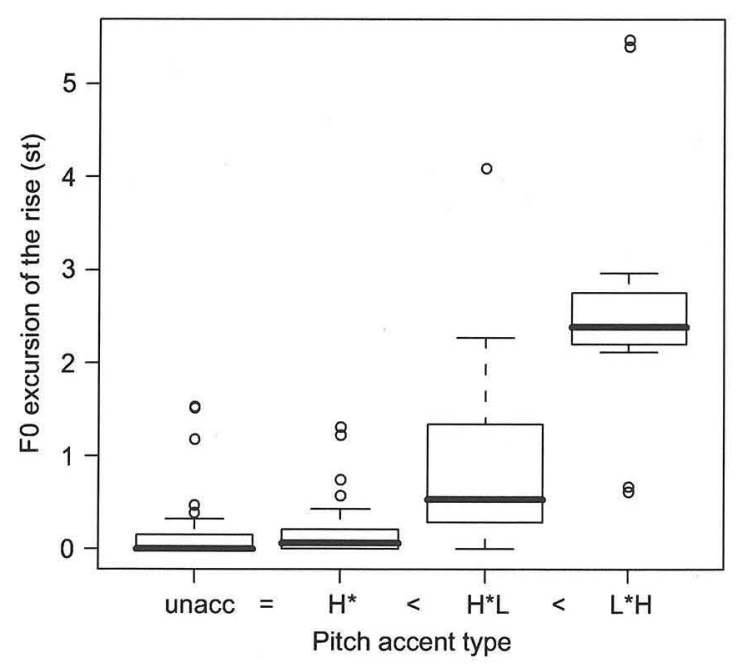

Fig. 6. Boxplot of the fo excursion of the rise in semitones for the English accents ' $<$ ' indicates a significant difference at $p<0.025$ between two accent types, while ' $=$ ' stands for 'no difference'). speaker and target words as crossed random variables. Since the variance for target words was effectively zero, this random variable was dropped. Data points for which the absolute standardized residuals were greater than 2.5 were removed as outliers and the model was refitted. $p$-Values were estimated as posterior probabilities based on a Markov Chain Monte Carlo simulation with 10,000 runs. If the factor pitch accent type was significant, separate posthoc comparisons between accent types were conducted by resetting the reference level in the model ( $p$-values were corrected for multiple analyses using Bonferroni adjustment).

Here we present only the minimal set of acoustic differences that are necessary to distinguish between all accent types. The f0-excursion of the rise differentiated the accents $\mathrm{H}^{*}, \mathrm{H}^{*} \mathrm{~L}$, and $\mathrm{L}^{*} \mathrm{H}$ (see Fig. 6, corrected $p$-value 0.025 ), but not $\mathrm{H}^{*}$ and no accent. However, an adverb with an $\mathrm{H}^{*}$ accent differed from an unaccented adverb in its relative duration $(1.22 \%$ of the duration of the verb for an accented now compared to $1.03 \%$ for an unaccented now, $p<0.05$ )

\subsection{Results}

As the adverb now and the object noun were separated by only two unstressed syllables, they might influence each other in intonational realization. We therefore consider the intonation realization of the object noun first and then the intonational realization of now. Finally, we will present a matrix showing the co-occurrences of pitch accent types in now and the object noun.

\subsubsection{Intonational realization of the object noun}

The distribution of intonation patterns in the object noun across conditions is presented in Table 1 . As expected, the noun was mostly accented with $\mathrm{H}^{*} \mathrm{~L}$ when the object was contrasted (89.7\% in ObjectContrast and $82.1 \%$ of the cases in DoubleContrast). When the object was not contrasted, it was mostly left unaccented (59.4\% of the cases) or was accented with $L^{*}(21.9 \%$ of the cases). As regards intonational phrasing, participants did not vary phrasing to signal the different contrast conditions. They produced a break after the object in 10 out of 29 cases in ObjectContrast, in 7 out of 32 cases in LocationContrast, and in 5 out of 28 cases in DoubleContrast.

\subsubsection{Intonational realization of the adverb now}

There were only four instances of an intonational phrase break following the adverb, two in LocationContrast and two in ObjectContrast. The absolute total number of tokens of each intonation pattern of now is provided in Table 2. As the total number of trials differed across conditions and across speakers, and speakers did not use all the intonation patterns equally frequently, we also report the mean percentage (\%) distribution of

Table 1

Absolute and relative numbers of intonation patterns in the object noun in each condition in English.

\begin{tabular}{|c|c|c|c|c|c|c|c|c|c|}
\hline \multirow[t]{2}{*}{ Condition } & & \multicolumn{8}{|c|}{ Pitch accent of object noun } \\
\hline & & $! \mathrm{H}^{*}$ & $! H^{*} \mathrm{~L}$ & $\mathrm{H}^{*}$ & $\mathrm{H}^{*} \mathrm{~L}$ & $\mathrm{~L}^{*}$ & $\mathrm{~L}^{*} \mathrm{H}$ & No accent & Total \\
\hline \multirow[t]{2}{*}{ LOCATIONCONTRAST } & $N$ & 1 & 2 & 1 & 1 & 7 & 1 & 19 & 32 \\
\hline & $\%$ & 3.1 & 6.2 & 3.1 & 3.1 & 21.9 & 3.1 & 59.4 & 100.0 \\
\hline \multirow[t]{2}{*}{ OBJECTCONTRAST } & $N$ & 0 & 0 & 0 & 26 & 1 & 1 & 1 & 29 \\
\hline & $\%$ & 0 & 0 & 0 & 89.7 & 3.4 & 3.4 & 3.4 & 100.0 \\
\hline \multirow[t]{2}{*}{ DOUBLECONTRAST } & N & 0 & 1 & 3 & 23 & 0 & 1 & 0 & 28 \\
\hline & $\%$ & 0 & 3.6 & 10.7 & 82.1 & 0 & 3.6 & 0 & 100.0 \\
\hline \multirow[t]{2}{*}{ Total } & $N$ & 1 & 3 & 4 & 50 & 8 & 3 & 20 & 89 \\
\hline & $\%$ & 1.1 & 3.4 & 4.5 & 56.2 & 9.0 & 3.4 & 22.5 & 100.0 \\
\hline
\end{tabular}


Table 2

The total number of occurrences and the mean \% distribution of each intonation pattern of now in each condition in English.

\begin{tabular}{lccccc}
\hline Condition & & $\mathrm{H}^{*}$ & $\mathrm{H}^{*} \mathrm{~L}$ & $\mathrm{~L}^{*} \mathrm{H}$ & No accent \\
\hline LocationContrast & $N$ & 9 & 4 & 10 & 9 \\
& $\%$ & 28.1 & 12.5 & 31.3 & 28.1 \\
ObjectContrast & $N$ & 9 & 4 & 0 & 16 \\
& $\%$ & 28.1 & 12.5 & 0 & 59.4 \\
DoubleContrast & $N$ & 5 & 4 & 2 & 17 \\
& $\%$ & 15.6 & 12.5 & 6.3 & 65.6 \\
\hline
\end{tabular}

each intonation pattern in each condition in Table 2. The mean percentage distribution of a given intonation pattern in a given condition was computed by averaging the percentages of the trials spoken with that accent type in the respective condition from all speakers. The most common patterns were 'no accent' and $\mathrm{H}^{*}$. In LocationContrast, $\mathrm{L}^{*} \mathrm{H}, \mathrm{H}^{*}$, and 'no accent' occurred with similar frequency. In ObJECTCONTRAst and DoubleContrast, now was most frequently unaccented.

To verify the distribution of intonation patterns in now over contrast conditions statistically, we carried out a multinomial logistic regression analysis (hereafter MLR) at the significance level of 0.05 . The independent variable (or the predictor variable) was contrast condition with three categories, LocationCONTRAST, ObjectContrast, and DoubleContrast. The dependent variable (or the outcome variable) was the intonation of now, consisting of four categories $\left(H^{*}, H^{*} L, L^{*} H\right.$, and 'no accent'). The accent $L^{*} H$ was used as the reference category because the distribution of $L^{*} H$ appeared to vary more clearly with contrast conditions compared to the other accent types. ${ }^{2}$

The by-chance accuracy in assigning the intonation patterns to the contrast conditions (calculated by summing up the squared proportion of cases of each intonation pattern in the data) was $31.85 \%$. The model fitting was improved significantly after the variable contrast condition was added (fit: $47.2 \%, \chi^{2}=14.60, \mathrm{df}=6$, $p<0.05$ ). This improvement supports a significant overall relationship between the contrast condition and the intonation of now.

The Wald statistics, comparable to the $t$-statistics in linear regressions, revealed that contrast condition significantly predicted the choice between an $\mathrm{H}^{*}$ and an $\mathrm{L}^{*} \mathrm{H}$ accent on now in ObjectContrast $(b=2.30$, Wald $=4.01, \mathrm{df}=1, p<0.05)$ compared to LocationContrast, and the choice between 'no accent' and $\mathrm{L}^{*} \mathrm{H}$ in ObjectContrast $(b=2.25$, Wald $=6.20, \mathrm{df}=1, p<0.05)$ and DoubleContrast $(b=2.81$, Wald $=6.60, \mathrm{df}=1, p<0.01)$ compared to LocationContrast. ${ }^{3,4}$ The odds ratios $(\operatorname{Exp}(B)$ values in the SPSS output) indicated first that the odds of now being spoken with $\mathrm{H}^{*}$ compared to the odds of now being spoken with $\mathrm{L}^{*} \mathrm{H}$ was 10 times higher in OBJEctContrast than in LOCATIONCONTRAST. ${ }^{5}$ Second, the odds

\footnotetext{
${ }^{2}$ Note that it was not possible to include speaker as a predictor variable because not every accent type was produced by every speaker.

${ }^{3}$ The absence of $\mathrm{L}^{*} \mathrm{H}$ on now in the object contrast condition made it impossible to examine the role of contrast condition in predicting the use of 'no accent' in now compared to the use of L* $\mathrm{H}$. We therefore introduced one fictive instance of now, accented with $\mathrm{L}^{*} \mathrm{H}$, into the object contrast condition by replacing one instance of unaccented now with $L^{*} H$ and ran the MLR analysis. This operation caused little changes to the Wald statistics concerning $\mathrm{H}^{*}$ and $\mathrm{H}^{*} \mathrm{~L}$ but generated interpretable results for the category no accent.

${ }^{4}$ The Wald statistic of a predictor or a predictor category is the value of the regression coefficient $(b)$ of the predictor (category) divided by its associated standard error.

${ }^{5}$ Odds are defined as the probability of an event occurring divided by the probability of an event not occurring. The odds ratio is the proportionate change in odds, calculated by dividing the odds after a unit change in the predictor by the odds before that change. It serves as an indicator of the change in odds resulting from a unit change in the predictor, similar to the $b$ coefficient but is easier to
}

Table 3

Co-occurrence of pitch accents of now (rows) and pitch accents in the object noun (columns).

\begin{tabular}{llllllll}
\hline \multirow{2}{*}{$\begin{array}{l}\text { Pitch accent type } \\
\text { of the adverb }\end{array}$} & \multicolumn{7}{l}{ Pitch accent type of the object noun } \\
\cline { 2 - 8 } & $! H^{*}$ & $! H^{*} \mathrm{~L}$ & $\mathrm{H}^{*}$ & $\mathrm{H}^{*} \mathrm{~L}$ & $\mathrm{~L}^{*}$ & $\mathrm{~L}^{*} \mathrm{H}$ & No accent \\
\hline $\mathrm{H}^{*}$ & 0 & 3 & 1 & 12 & 3 & 0 & 4 \\
$\mathrm{H}^{*} \mathrm{~L}$ & 0 & 0 & 0 & 8 & 0 & 0 & 4 \\
$\mathrm{~L}^{*} \mathrm{H}$ & 1 & 0 & 1 & 2 & 3 & 0 & 6 \\
No accent & 0 & 0 & 3 & 28 & 2 & 3 & 6 \\
Total & 1 & 3 & 4 & 50 & 8 & 3 & 20 \\
\hline
\end{tabular}

of now being spoken with 'no accent' was 16.67 times higher than the odds of now being spoken with $L^{*} \mathrm{H}$ in OBjectConTRAST than in LocationContrast. ${ }^{6}$ Third, the odds of now being spoken with 'no accent' was 9.44 times higher than the odds of now being spoken with $\mathrm{L}^{*} \mathrm{H}$ in DoubleContrast than in LocationContrast.

\subsubsection{Co-occurrence of pitch accents}

Table 3 shows the frequency with which a certain pitch accent on now is followed by a certain pitch accent in the object noun to address the issue of whether the observed intonation patterns in now might be due to the avoidance of an accent clash.

As can be seen in Table 3, an accented now is followed by an accented object noun in 34 cases but by an unaccented object noun in only 14 cases. Conversely, an accented object noun was preceded by an accented now in 33 cases and by and unaccented now in 36 cases.

\subsection{Discussion}

The English production data show that speakers varied the intonation of now, but not phrasing, to disambiguate the locus of the contrast (i.e., whether the object was contrasted or not). The number of contrasts, however, was not signaled at all. By and large, now was preferably unaccented or accented with $\mathrm{H}^{*}$ when the object was contrasted, independent of whether the location was contrasted at the same time. On the other hand, now was preferably accented with $\mathrm{L}^{*} \mathrm{H}$ when the object was not contrasted. Intonation of now hence only signaled whether the object was contrasted or not, similar to the patterns we observed in the experimental materials used by Dahan et al. (2002) and Chen et al. (2007).

Strikingly, English speakers did not use phrasing or the intonation in the object noun to differentiate between a contrast in the object and a double contrast in the object and the location. In both cases, the object noun was realized with a pitch fall $\left(\mathrm{H}^{*} \mathrm{~L}\right)$, sometimes with a phrase break, but mostly without. Therefore it is not surprising that native speakers of English sometimes had difficulties telling these two conditions apart.

Since a contrasted object is mostly accented, the preference for an unaccented now in conditions with a contrasted object might be phonologically conditioned: To avoid an accent clash between

\section{footnote continued)}

interpret because it does not involve a logarithmic transformation. If the odds ratio is larger than 1 , it indicates that as the predictor increases, the odds of the outcome occurring increases. If the odds ratio is smaller than 1 , it indicates that as the predictor increases, the odds of the outcome occurring decreases (Field, 2009).

${ }^{6}$ Conversely, the odds of now being spoken with $\mathrm{L}^{*} \mathrm{H}$ compared to the odds of now being spoken with $\mathrm{H}^{*}$ was higher in LocationCoNTRAST. This was somewhat unexpected given that $\mathrm{H}^{*}$ and $\mathrm{L}^{*} \mathrm{H}$ seemed to occur with similar frequency (see Table 1). A closer inspection of the within-speaker distribution of $\mathrm{L}^{*} \mathrm{H}$ and $\mathrm{H}^{*}$ revealed that only four speakers produced $L^{*} H$ and five speakers produced $H^{*}$. Importantly, $L^{*} H$ was the most frequent accent type in LocationContrast in all the four speakers who produced this accent, whereas $\mathrm{H}^{*}$ was the most frequent accent type in only two out of the five speakers who used this accent. This suggests that the preference for $\mathrm{L}^{*} \mathrm{H}$ over $\mathrm{H}^{*}$ in LocationCONTRAST was a speaker-specific effect. 
now and the object noun, the realization of now may be toned down $\left(\mathrm{H}^{*}\right.$ or 'no accent'). ${ }^{7}$ The opposite can be argued for the frequent use of a prominent rise $\left(\mathrm{L}^{*} \mathrm{H}\right)$ in now in LocationConTRAST, where the object noun was mostly unaccented or accented with an $L^{*}$, which made it possible for now to be accented. However, this accent-clash-avoidance assumption is not born out by the data. As can be seen in the co-occurrence matrix of pitch accents in now and the object in Table 3, an accented now was more often followed by an accented object noun than by an unaccented one. Conversely, an accented object was equally often preceded by an accented now as by an unaccented now.

Hence, an unaccented now appears to be a marker for an immediate contrast (in the present materials a contrasting object), while an $L^{*} H$ signals that the contrast will appear only later in the sentence (in our materials a contrast in location). Such a function of $\mathrm{L}^{*} \mathrm{H}$ in now fits well with the function of a rising nuclear contour (a rising nuclear pitch accent plus a high boundary tone) as a cue to continuation in general in English (Cruttenden, 1997; Pierrehumbert, 1981). Alternatively, since the salience of these two constituents, the object and the location, is not the same (in syntactic theory, objects are usually treated as more salient than local adverbials, cf. obliqueness hierarchy by Keenan \& Comrie, 1977), an unaccented now can be interpreted as a marker for a contrast in a salient constituent (in the present materials the object), and $\mathrm{L}^{*} \mathrm{H}$ as a marker for a contrast in a less salient constituent (e.g., the location). However, the present data do not allow us to decide between these two accounts as sequential order is confounded with grammatical role (i.e., the object always preceded the location).

\section{Dutch production experiment}

\subsection{Methods}

\subsubsection{Materials}

The materials were identical to the ones described in Section 3.1.1.

\subsubsection{Participants}

Twenty-two native Dutch speakers (11 female and 11 male, students at Radboud University Nijmegen) took part in the study. They were unaware of the purpose of the experiment and received a small fee for their participation.

\subsubsection{Procedure}

The procedure was identical to the one described in Section 3.1.3. Dutch participants were tested in a sound-attenuated booth at the MPI in Nijmegen. The productions were recorded on DAT-tapes with a sampling rate of $48 \mathrm{kHz}$ and a resolution of 16-bit.

\subsection{Analysis and results}

\subsubsection{Word order}

The second sentence in each pair of instructions was annotated on the word level for the verb (verplaats), the adverb $(n u)$, the target object to be moved, and the location ( $v a k n$ or just the number). Two word orders occurred in Dutch speakers' productions, Verplaats $n u$ de $X$ naar vak $Y$ (lit: 'Put now the $X$ in cell $Y$ ') and Verplaats de $X n u$ naar vak $Y$ (lit: 'Put the $\mathrm{X}$ now in cell $\mathrm{Y}$ '). The former was the dominant one across conditions and was used in $89 \%$ of the cases. At first glance, this result looked striking, given that Dutch speakers have the option to exploit word order variations to partly disambiguate the conditions. At second glance, however, it was

\footnotetext{
${ }^{7}$ Note that in IViE, $\mathrm{H}^{*}$ is a high level tone or a slightly rising contour, which is perceptually a relatively weak accent.
}

not completely unexpected as the dominant word order was the one that received the highest acceptability scores overall. Some speakers used one word order throughout, independent of contrast condition ( 3 males and 9 females, 'fixed word order group' henceforth), others made use of word order variation (8 males and 2 females, 'variable word order group' henceforth).

We will first discuss the intonational realization of $n u$ for the 'fixed word order group' in the same fashion as done for English now to answer the question whether underlying differences in word order flexibility affect the degree to which prosody is used to disambiguate the contrast conditions. Then we will present a descriptive intonational analysis of the productions from the 'variable word order group' to get an insight of how choice of word order interacts with the prosodic realization of $n u$.

\subsection{2. 'Fixed word order group' (Verb nu Object Location)}

To have a sample size comparable to the data analyzed for English, we selected 8 female speakers who only produced the dominant word order. The Dutch productions analyzed here hence only differed from the English ones in the relative order between verb and adverb.

Sixteen of the second instructions had to be discarded because of hesitations and absence of the adverb. Following this selection procedure, 80 second instructions were selected for further analysis (28 in LocationContrast, 24 in OBjectContrast, and 28 in DoubleContrast). Similar to the English data, these second instructions were presented to five native speakers of Dutch for evaluation. The evaluation procedure was the same as described for English. The utterances were classified correctly by the majority of these judges (three or more) in $83.8 \%$ of the cases, which is similar to the classification rate for English utterances (85.9\% of the cases). The small number of misclassifications was again restricted to interpreting the intended object or location contrast as a double contrast.

4.2.2.1. Phonological analysis. The 80 second instructions were prosodically annotated following ToDI. Like its English counterpart IViE described in Section 3.2.1, ToDI only transcribes the tonal movement on and following the stressed syllable and the tonal movement at intonation phrase boundaries. However, initial inspection of the pitch tracks revealed differences in the tonal movement leading up to the starred tone of $n u$. These differences were caused by the tonal transition from the verb preceding the adverb to the adverb itself (verplaats $n u$ ) and might therefore not be captured by the phrase-initial boundary tone (as this boundary tone does not sufficiently specify the tonal realization of the verb). In order not to lose potentially useful information about the intonation of $n u$, we decided to extend the set of ToDI categories by adding two more accent types $\left(\mathrm{LH}^{*}-\mathrm{a}\right.$ high level tone preceded by a low tone, and $\mathrm{LH}^{*} \mathrm{~L}-\mathrm{a}$ fall preceded by a low tone). There were hence five accent types for the intonation of $n u$ (see Table A1 in the Appendix). The annotation procedure was the same as described for English.

Example pitch tracks are shown in Figs. 7 and 8.

4.2.2.2. Phonetic analysis. The f0-excursion of the rise was calculated from the mid of the stressed vowel /a/ of the verb verplaats to the f0-maximum in $n u$. The other variables were identical to the English measurements. The predictors and the model fitting were identical to those of the English data. Fig. 9 shows box plots of the f0-excursion of the rise for all accent types, including 'no accent'. For this analysis, posthoc comparisons were conducted with $\mathrm{H}^{*}, \mathrm{LH}^{*}$, and $\mathrm{L}^{*} \mathrm{H}$ as reference levels. The corresponding $p$-value was corrected to 0.016 . Results showed that f0-excursion 


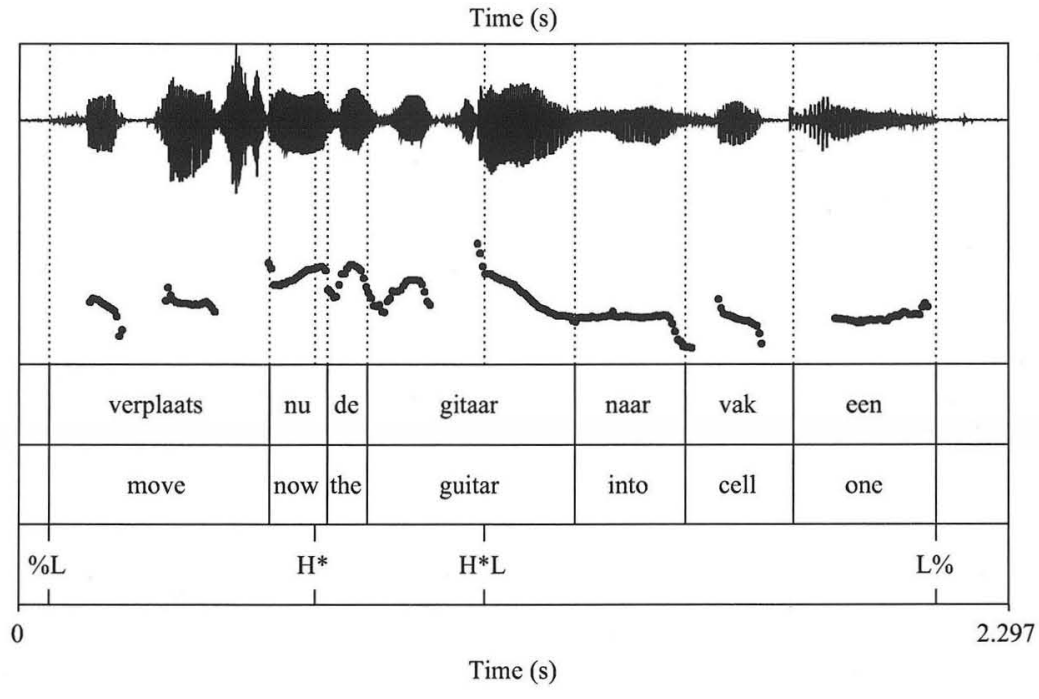

Fig. 7. Pitch track of an utterance in ObjectContrast produced by a Dutch speaker.

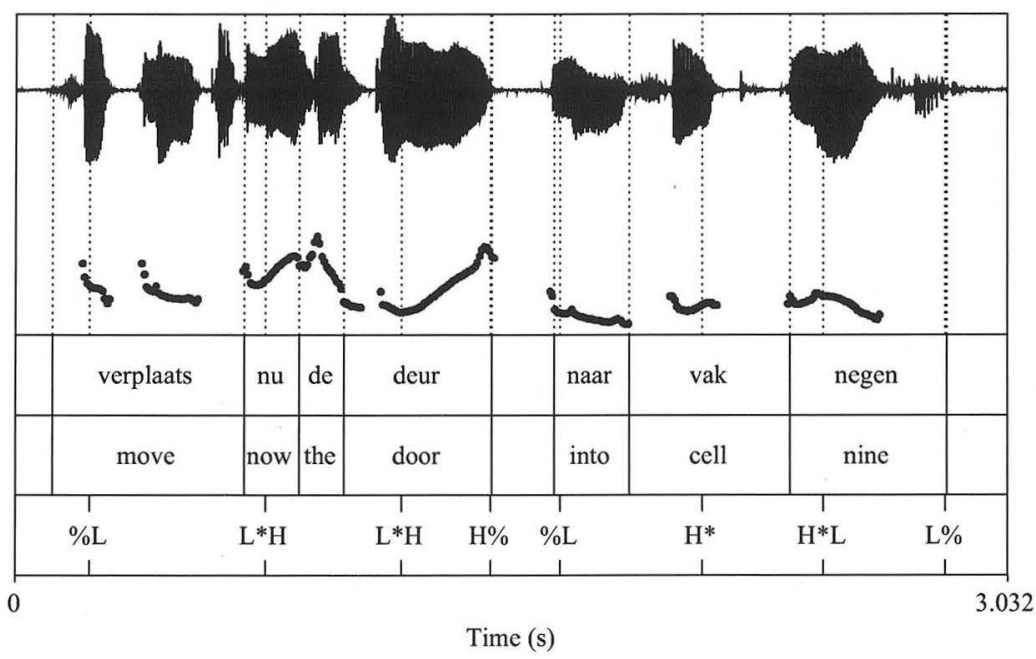

Fig. 8. Pitch track of an utterance in LocationContrast produced by a Dutch speaker.

of the rise was largest for $\mathrm{L}^{*} \mathrm{H}$, followed by $\mathrm{LH}^{*}$ and $\mathrm{LH}^{*} \mathrm{~L}$, and smallest for 'no accent', $\mathrm{H}^{*}$ and $\mathrm{H}^{*} \mathrm{~L}$.

As can be seen in Fig. 10, the two pairs of accent types that did not differ in the f0-excursion of the rise $\left(\mathrm{LH}^{*}\right.$ and $\mathrm{LH}^{*} \mathrm{~L}$ as well as $\mathrm{H}^{*}$ and $\mathrm{H}^{*} \mathrm{~L}$ ) differed in the f0-excursion of the fall. The excursion of the fo-fall was significantly larger in $\mathrm{H}^{*} \mathrm{~L}$ compared to $\mathrm{H}^{*}$ and in $\mathrm{LH}^{*} \mathrm{~L}$ compared to $\mathrm{LH}^{*}$, i.e., the fall was significantly more pronounced in accent types with a low trailing tone (corrected $p$-value 0.025).

Final analysis showed that an adverb with an $\mathrm{H}^{*}$ accent was significantly longer than an unaccented one (31\% of the duration of the verb for an accented adverb compared to $26 \%$ of the duration of the verb for an unaccented one). A summary of the alignment, scaling, and duration measures is provided in Table $A 3$ in the Appendix.

4.2.2.3. Results. The presentation of Dutch results follows the same ordering as for the English results.

Intonational realization of the object noun: The distribution of pitch accent types in the object noun across conditions is presented in Table 4. Similar to English, the most frequent accent type for ObjectContrast was $\mathrm{H}^{*} \mathrm{~L}$ (70.8\% of the cases). In DoubleContrast, participants used $\mathrm{L}^{*} \mathrm{H}$ most frequently (35.7\% of the cases), followed by $\mathrm{H}^{*} \mathrm{~L}$ ( $25 \%$ of the cases). For LocationContrast, the most frequent accent types were $L^{*} H\left(25.0 \%\right.$ of the cases), followed by $H^{*}$ (21.4\%) and 'no accent' (17.9\%). Further, Dutch speakers, like English speakers did not vary phrasing after the object noun to differentiate the contrast conditions. They produced 15 breaks in LocationContrast and OBjectContrast (out of 28 and 24, respectively), and 12 breaks (out of 28) in DoubleContrast.

Intonational realization of the adverb nu: There were five instances of an intonational break following the adverb, two in LocationContrast and DoubleContrast each, one in ObjectContrast. The frequency of intonational breaks after $n u$ was not affected by contrast condition $\left(\chi^{2}=0.3, \mathrm{df}=2, p>0.8\right)$. In what follows, we will present the results on pitch accent types of $n u$.

The intonational realizations of $m u$ (absolute numbers and mean percent distribution) are shown in Table 5. In LocationCONTRAST, $n u$ was mostly accented; the most common accent types were rising accents, i.e., $\mathrm{LH}^{*}$ and $\mathrm{L}^{*} \mathrm{H}$. In OBJECTCONTRAST, however, $n u$ was most frequently unaccented. In the DoubleContrast condition, unaccented $n u$ and $n u$ accented with $\mathrm{LH}^{*}$ occurred more frequently than the other patterns.

As in the English data, an MLR analysis was conducted on the Dutch data at the significance level of 0.05 . The dependent variable was the intonation of $n u$, consisting of six categories $\left(\mathrm{H}^{*}, \mathrm{H}^{*} \mathrm{~L}, \mathrm{~L}^{*} \mathrm{H}\right.$, 


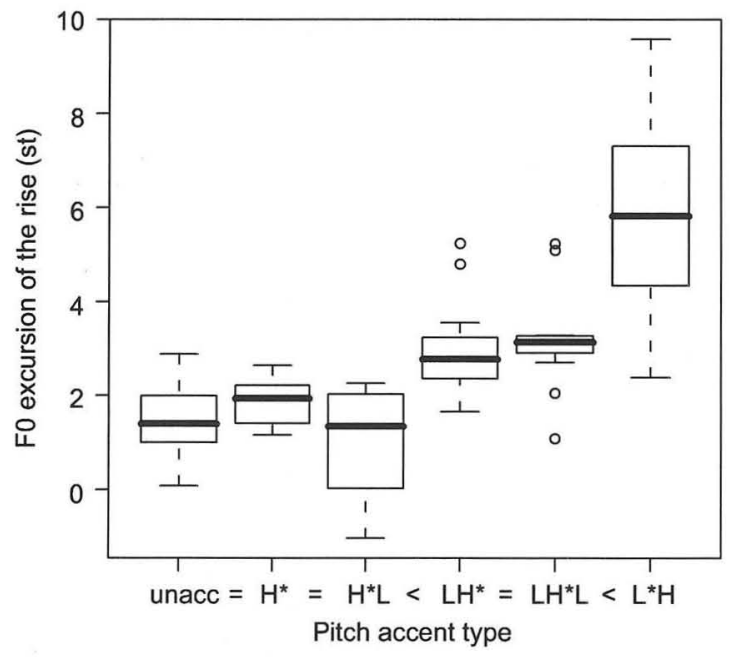

Fig. 9. Boxplot of the fo excursion of the rise in semitones for Dutch pitch accent types (' $<$ ' indicates a significant difference at $p<0.016$ between two accent types, while ' $=$ ' stands for 'no difference').

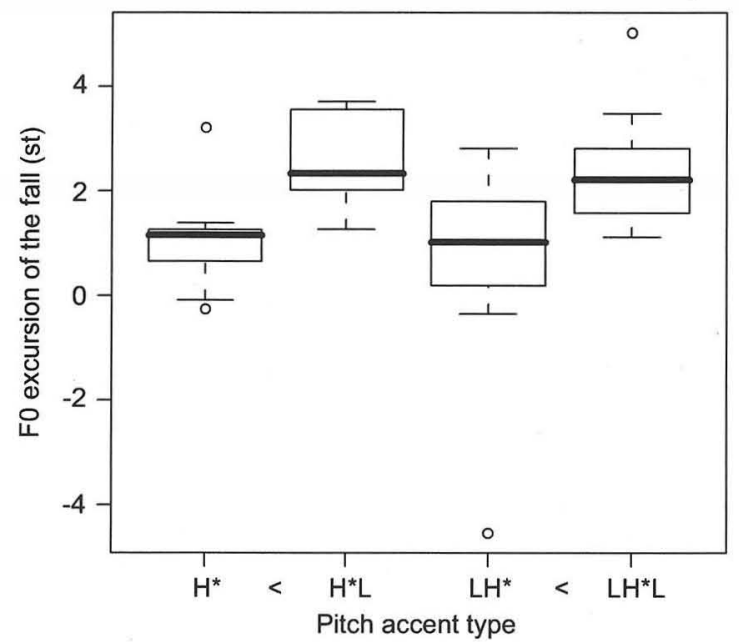

Fig. 10. Boxplot of the fo excursion of the fall in semitones for those Dutch pitch accents that did not differ in the f0 excursion of the rise ( $<$ ' indicates a significant difference at $p<0.025$ between two accent types, while ' $=$ ' stands for 'no difference').

Table 4

Absolute and relative numbers of intonation patterns in the object noun in each condition in Dutch.

\begin{tabular}{lcccccccc}
\hline Condition & \multicolumn{7}{c}{ Pitch accent of object noun } \\
\cline { 2 - 9 } & & $! \mathrm{H}^{*}$ & !H* $\mathrm{L}$ & $\mathrm{H}^{*}$ & $\mathrm{H}^{*} \mathrm{~L}$ & $\mathrm{~L}^{*} \mathrm{H}$ & No accent & Total \\
\hline LocationContrast & $N$ & 4 & 5 & 6 & 1 & 7 & 5 & 28 \\
& $\%$ & 14.3 & 17.9 & 21.4 & 3.6 & 25.0 & 17.9 & 100.0 \\
ObjectContrast & $N$ & 0 & 3 & 2 & 17 & 2 & 0 & 24 \\
& $\%$ & 0 & 12.5 & 8.3 & 70.8 & 8.3 & 0 & 100.0 \\
DoubleContrast & $N$ & 2 & 2 & 5 & 7 & 10 & 2 & 28 \\
& $\%$ & 7.1 & 7.1 & 17.9 & 25.0 & 35.7 & 7.1 & 100.0 \\
Total & $N$ & 6 & 10 & 13 & 25 & 19 & 7 & 80 \\
& $\%$ & 7.5 & 12.5 & 16.2 & 31.2 & 23.8 & 8.8 & 100.0 \\
\hline
\end{tabular}

LH* $\mathrm{LH}^{*} \mathrm{~L}$, and 'no accent'); like in English the reference category was also set to $L^{*} H$. The independent variable was contrast with three categories, LocationContrast, ObjectContrast, and DoubleContrast.

The by-chance accuracy in assigning the intonation patterns to the contrast conditions was $18.69 \%$. The model fitting was
Table 5

The total number of occurrences and the mean \% distribution of each intonation pattern of $n u$ in each condition in Dutch.

\begin{tabular}{lccccccc}
\hline Condition & & $\mathrm{H}^{*}$ & $\mathrm{H}^{*} \mathrm{~L}$ & $\mathrm{~L}^{*} \mathrm{H}$ & $\mathrm{LH}^{*}$ & $\mathrm{LH}^{*} \mathrm{~L}$ & No accent \\
\hline LocationContrast & $\mathrm{N}$ & 3 & 1 & 7 & 11 & 5 & 1 \\
& $\%$ & 11.5 & 3.1 & 31.3 & 40.5 & 15.6 & 3.1 \\
ObjectContrast & $N$ & 4 & 1 & 1 & 3 & 4 & 11 \\
& $\%$ & 17.7 & 3.1 & 4.2 & 14.3 & 16.7 & 45.8 \\
DoubleContrast & $N$ & 4 & 4 & 3 & 5 & 5 & 7 \\
& $\%$ & 14.6 & 14.6 & 9.4 & 23.8 & 16.7 & 24.0 \\
\hline
\end{tabular}

Table 6

Co-occurrence of pitch accents of $n u$ (rows) and pitch accents in the object noun (columns).

\begin{tabular}{llccccc}
\hline \multirow{2}{*}{$\begin{array}{l}\text { Pitch accent type } \\
\text { of the adverb }\end{array}$} & \multicolumn{6}{l}{ Pitch accent type of the object noun } \\
\cline { 2 - 7 } & $! \mathrm{H}^{*}$ & $! \mathrm{H}^{*} \mathrm{~L}$ & $\mathrm{H}^{*}$ & $\mathrm{H}^{*} \mathrm{~L}$ & $\mathrm{~L}^{*} \mathrm{H}$ & No accent \\
\hline $\mathrm{H}^{*}$ & 0 & 0 & 0 & 7 & 2 & 2 \\
$\mathrm{H}^{*} \mathrm{~L}$ & 0 & 1 & 1 & 1 & 3 & 0 \\
$\mathrm{~L}^{*} \mathrm{H}$ & 1 & 0 & 2 & 2 & 5 & 1 \\
$\mathrm{LH}^{*}$ & 2 & 4 & 6 & 2 & 4 & 1 \\
$\mathrm{LH}^{*} \mathrm{~L}$ & 1 & 1 & 3 & 6 & 2 & 1 \\
No accent & 2 & 4 & 1 & 7 & 3 & 2 \\
Total & 6 & 10 & 13 & 25 & 19 & 7 \\
\hline
\end{tabular}

improved significantly after the variable contrast condition was added (fit: $36.2 \%, \chi^{2}=23.10, \mathrm{df}=10, p=0.01$ ), indicating a significant overall relationship between the contrast condition and the intonation of $n u$.

The Wald statistics showed that contrast condition significantly distinguished the tokens of $n u$ spoken with 'no accent' from those spoken with $\mathrm{L}^{*} \mathrm{H}$ (reference category) $(b=4.34$, Wald $=8.45, \mathrm{df}=1$, $p<0.005$ in OBjectContrast, $b=2.79$,Wald $=4.82, \mathrm{df}=1, p=0.05$ in DoubleContrast). The odds ratios showed that the odds of $m u$ being spoken with 'no accent' was 77 times higher than the odds of $n u$ being spoken with L*H in OBJECTCONTRAST compared to LoCATIONCONTRAST. Similarly, the odds of $m u$ being spoken with 'no accent' compared to the odds of $n u$ being spoken with $\mathrm{L}^{*} \mathrm{H}$ was 16 times higher in DOUBLECONTRAST than in LOCATIONCONTRAST. These results largely support the observations from the mean percent distribution of accent types.

Co-occurrence of pitch accents: Table 6 shows the co-occurrence matrix between the intonational realization of the adverb and the pitch accent types observed in the object noun.

An accented nu was followed by an accented object noun in 54 cases but by an unaccented object noun in only 5 cases. Conversely, an accented object noun was preceded by an accented $n u$ in 54 cases but by an unaccented $n u$ in only 17 cases.

\subsection{3. 'Variable word order group'}

Excluding 10 cases with hesitations or no $\mathrm{nu}$, the 10 speakers from the 'variable word order group' provided 29 second instructions in the non-dominant word order, in which nu followed the object (e.g., 'Verplaats de baby nu naar vak 1'), and 89 second instructions in the dominant word order (e.g., 'Verplaats nu de baby naar vak 1'). One female speaker produced the non-dominant word order throughout, independent of contrast condition. The other nine speakers used this word order more frequently in LOCATIONCONTRAST ( 7 out of 31 cases) and DoubleContrast ( 9 out of 31 cases) than in ObjectContrast ( 1 out of 27 cases), $\chi^{2}=7.4, \mathrm{df}=2, p<0.05$.

The second instructions were prosodically annotated as described in Section 4.2.2.1 The distribution of intonational patterns of $n u$ in the 89 trials with the dominant word order were similar to that reported for the trials produced by the 'fixed word order group' in Section 4.2.2.3, see Table A4 in the Appendix. 
Table 7

Intonation and phrasing of $n u$ in non-dominant word order (verb noun nu location).

\begin{tabular}{llllll}
\hline & \multicolumn{3}{l}{ Rising accents } & & \\
\cline { 2 - 6 } & $\mathrm{H}^{*} \mathrm{~L}$ & $\mathrm{~L}^{*} \mathrm{H}$ & $\mathrm{H}^{*} \mathrm{LH} \%$ & $\mathrm{H}^{*}$ & No accent \\
\hline $\begin{array}{l}\text { LocationContrast } \\
\begin{array}{l}\text { ObjectContrast } \\
\text { DoubleContrast }\end{array}\end{array}$ & 5 & 2 & 1 & 1 \\
\hline
\end{tabular}

In the 21 second instructions produced in the non-dominant word order, the speakers varied phrasing across conditions. In LocationConTRAST, there was mostly a break after the adverb, i.e., before the location ( 9 out of 11 cases), in OBJEcTCONTRAST, there was mostly a break before the adverb, i.e., after the object ( 3 out of 5 cases), but there was no preference between these two options in DoubleContrast (see Table A5 in the Appendix).

Regarding the intonational realization of the adverb in sentences with the non-dominant word order, we found that nu was consistently produced with rising accents (mostly L*H but also $\mathrm{H}^{*}$ followed by a high boundary tone) in LOCATIONCONTRAST but was mostly unaccented in ObjectContrast. In DoubleContrast there was no clear preference for one kind of accent over the others (see Table 7). These patterns were similar to the patterns in the sentences with the dominant word order produced by the 'fixed word order group'.

\subsection{Discussion}

A third of the Dutch speakers appeared to make use of word order variation to signal the contrast condition. There were more instances in which $n u$ was placed before the location in LocationContrast and DoubleContrast than in ObjectContrast. The majority of the speakers placed $n u$ after the verb, independent of contrast condition. The preponderance of placing $n u$ after the verb is somewhat surprising, given the option to vary the word order to signal the different contrast conditions. Possibly, the repeated production of instructions demanding the dominant word order (i.e., OBJECtCONTRAST and DOUBLECONTRAST) triggered syntactic priming (e.g., Bock, 1986), i.e., the preference to repeat the same word order across trials, also in LOCATIONCONTRAST.

Independent of choice of word order, Dutch speakers varied the intonation in the object noun to differentiate a single contrast in the object from a double contrast. In double contrast, they used a higher proportion of rising accents $\left(L^{*} H\right)$, while they overwhelmingly used a pitch fall $\left(\mathrm{H}^{*} \mathrm{~L}\right)$ in OBJECTCONTRAST. As argued in Section 3.4, the use of the pitch rise may signal continuation, which may in this case be used as a hint for the listener that there is another contrast to come.

The use of phrasing covaried with the choice of word order. In the dominant word order (e.g., Verplaats nu het boek naar vak 3), Dutch speakers did not vary phrasing after nu to mark the contrast conditions. However, in the non-dominant word order (e.g., Verplaats het boek nu naar vak 3), they produced an intonational break more frequently after $n u$ (and before the location) when the location was contrasted but more frequently before $n u$ (and after the object) when only the object was contrasted. This result suggests that Dutch speakers had the tendency to prosodically isolate the contrasted constituent. Furthermore, it suggests that phrasing was used in tandem with word order scrambling to disambiguate contrast conditions - at least by some Dutch speakers. The finding that speakers not only altered the word order but also prosody for information structural purposes is not uncommon. For example, in many languages, the fronting of focal elements (e.g., It was PETER who left) is accompanied by prosodic salience (e.g., Prince, 1978).
Interestingly, the use of intonation variation in nu to signal the locus of the contrast was largely independent of word order, similar to the use of intonational variation in the object noun. $\mathrm{Nu}$ was predominantly produced with rising accents (mostly $\mathrm{L}^{*} \mathrm{H}$ ) when the location was contrasted; but it was mostly unaccented or spoken with $\mathrm{H}^{*}$ when only the object was contrasted. Apparently, both word orders can be used in each of the three contrast conditions if the prosodic realization of $n u$ (and the object noun) is chosen appropriately. This flexibility in word order may be the key to understanding the perplexing fact that the appropriateness ratings obtained from the web experiment and the distribution of the dominant and non-dominant word orders in actual productions do not resemble each other more. Positioning $n u$ before the location is more likely to signal a contrast in location or a double contrast but at the same time, this word order (though with a different prosodic realization) may also signal a contrasting object. Since prosody was not controlled in the acceptability rating experiment, the judges probably projected their own prosody onto the sentences and rendered a less common word order in a certain contrast condition acceptable.

Dutch speakers mostly produced an unaccented nu when the object was contrasted but an $\mathrm{L}^{*} \mathrm{H}$ accented $n u$ when only the location was contrasted, which again poses the question as to whether this is simply a strategy to avoid an accent clash in two neighboring constituents. The co-occurrence patterns of the accentual realization of $n u$ and the object noun (Table 6) shows, however, that the combination of an accented $n u$ and an accented object is 3 times more likely than the combination between an unaccented $n u$ and an accented object. A further argument against the accent-clash-avoidance hypothesis is the observation that the intonational realization of $n u$ was independent of word order.

In Dutch, the intonation of $n u$ is not varied as a function of the proximity of an upcoming contrast. If this were the case, we would have expected an unaccented nu for a contrast in location in the non-dominant word order. This is however not what we found. The Dutch data actually suggest that $\mathrm{L}^{*} \mathrm{H}$ is a device to prepare the listener for a less expected contrast, i.e., a contrast in a syntactically less salient, more oblique, constituent (the location), while an unaccented nu signals a contrast in a syntactically more salient, less oblique, constituent (the object). This speculative connection between the obliqueness of syntactic constituents (Keenan \& Comrie, 1977) and the degree to which participants expect a contrast in that constituent is supported by results from eye-tracking experiments with these kinds of instructions, which have shown an initial bias towards a contrasting object (Braun \& Chen, 2008; Dahan et al., 2002). Nevertheless, further empirical backing is needed to substantialize our speculation.

\section{General discussion}

Despite the attested differences in word order flexibility of Now to signal upcoming contrasts, Dutch and English speakers' prosodic realization of Now was remarkably similar. Neither group of speakers relied on phrasing to disambiguate the contrast conditions (contrast in object, location or both) but both groups of speakers systematically varied the intonational realization of NOW to mark the locus of the contrast. When the object was contrasted, the adverb was preferably unaccented or accented with a high level tone $\left(\mathrm{H}^{*}\right)$ but when only the location was contrasted, the adverb was mostly realized with a low rise $\left(\mathrm{L}^{*} \mathrm{H}\right)$, in accordance with the patterns we observed in the experimental materials used by Dahan et al. (2002) and Chen et al. (2007).

The observed intonational patterns in Now in the different contrast conditions cannot satisfactorily be explained by an accent-clash-avoidance strategy (not accenting now when the 
object is contrasted and therefore accented, accenting now when the object is given and therefore not accented). In fact, in English, an accented object was equally often preceded by an accented and by an unaccented now. In Dutch, an accented object was three times as often preceded by an accented than by an unaccented $n u$. These data hence call for a functional, rather than a purely phonological explanation. One tentative explanation is elaborated in the following paragraph, drawing on observations on the interplay between word order and intonation.

Dutch speakers have the possibility to vary their word order for scope disambiguation, but in our study only a few speakers made use of word order variation. Strikingly, however, Dutch speakers' unaccented $n u$ for a contrast in the object and an $L^{*} H$ accented $n u$ for only a contrast in the location - was independent of word order choice. This is an indication that the intonational realization of $n u$ does not signal the immediacy of the contrast (whether it lies in the immediate constituent or in a constituent further away). Rather, it is conceivable that speakers produce $n u$ with a comparatively prominent rising accent $\left(\mathrm{L}^{*} \mathrm{H}\right)$ to signal that the contrast lies in a less salient, more oblique, constituent (here, the location, cf. Keenan \& Comrie, 1977). On the other hand, speakers do not strongly mark $n u$ with an accent if the contrast is found in a highly salient constituent (here, the object). This hypothesis ties in nicely with results from eye-tracking experiments showing that listeners tend to have a bias towards a contrast in the object (Braun \& Chen, 2008; Dahan et al., 2002), However, as the experiments were not designed to test and compare these two interpretations and the sample of realizations with $n u$ placed before the location was small in the current study, further research is needed to give a definitive answer to the question as to whether the intonation of $n u$ is sensitive to the obliqueness of the arguments.

Regarding the number of contrasts, English speakers and the majority of Dutch speakers did not vary the prosodic realization of Now (phrasing and intonation) to disambiguate a single contrast in the object from a double contrast. This suggests that it is contrasted or not. Marking only whether there is a contrast in the object and not whether there is yet another contrast to come can be beneficial for both the listener and the speaker. For the listener, it would undoubtedly be difficult to distinguish three (or even more) meaningfully different pitch accents on such a short adverb. Furthermore, knowing whether to expect a contrast in the following constituent or not may speed up choice of accent type on $n u$ to signal the locus of the contrast more important for speakers to mark whether the object is

speech comprehension. For the speaker, it means that he or she need not plan the entire clause but may focus on the local structure. Whether there is an additional contrast later on may then be signaled by the prosodic realization of the object. This was indeed the case in our Dutch data. Dutch speakers, mostly produced a rising accent on the contrasted object when there was a further contrast in the location, but a fall when only the object was contrasted. It is however perplexing that we did not observe this use of intonation in the object noun in English speakers.

To conclude, the present data show that at least some Dutch speakers used word order to disambiguate the contrast conditions. Irrespective of their choice of word order, both Dutch speakers and English speakers varied the intonation of Now to mark the upcoming contrasts. The intonation of Now was primarily varied to signal the locus of the contrast (object vs. location), not the number of contrasts. This result was explained from a processing perspective. Surprisingly, differences in underlying word order flexibility did not influence the extent to which intonational variation in Now was used. The exact choices of intonation patterns appear to be motivated by the salience of the contrasted constituent: Now is unaccented if the contrast lies in a salient constituent (here the object), while it is accented with a prominent rise to signal a contrast in a less salient constituent (the location). This study extends our knowledge on the functions of the prosodic variations of the sequential adverb now/nu and adds to the body of literature on the interface between prosody and information structure, which has been mostly based on the prosodic realization of discourse referents (e.g., Brazil, 1975; Gussenhoven, 1984; Pierrehumbert and Hirschberg, 1990; Steedman, 2000) and focus particles (e.g., Krifka, 1991; Reis \& Rosengren, 1997).

\section{Acknowledgements}

We are grateful to Sam Hellmuth (University of York), Fang Liu (University of Chicago and University of London) for help with data collection. Further, we would like to thank Alice Kruisselbrink and Marieke Hoetjes for making the movie clips, Mirjam Sparreboom for annotating the English and Dutch data at the word level, and Neil Forsyth for proofreading an earlier version of the manuscript.

\section{Appendix A}

Table A1

Accent types used for the intonational annotation of the adverb. The square in the stylization indicates the syllable. Standard IViE accent types, which were used for the annotation of British English now, are marked in bold face.

Accent type


Table A2

Mean (and sd) of acoustic measurements the pitch accent types of now.

\begin{tabular}{lrrr}
\hline & $\mathrm{H}^{*}$ & $\mathrm{H}^{*} \mathrm{~L}$ & $\mathrm{~L} \mathrm{~L}^{*} \mathrm{H}$ \\
\hline f0-excursion of the rise in st & $0.23(0.38)$ & $0.99(1.19)$ & $2.64(1.49)$ \\
f0-excursion of the fall in st & $0.95(0.81)$ & $4.81(1.81)$ & $0.50(0.60)$ \\
Relative duration of nu (divided by verb duration) & $1.30(0.28)$ & $1.81(0.65)$ & $1.27(0.52)$ \\
Alignment of the fo-maximum with respect to syllable onset in ms & $120.6(145.4)$ & $87.0(49.1)$ & $206.3(63.4)$ \\
Alignment of the f0-minimum with respect to syllable onset in ms & $109.5(70.7)$ & $1.00(0.35)$ \\
\hline
\end{tabular}

Table A3

Mean (and sd) of phonetic variables for the different Dutch pitch accent types.

\begin{tabular}{|c|c|c|c|c|c|c|}
\hline & $\mathrm{H}^{*}$ & $\mathrm{H}^{*} \mathrm{~L}$ & $\mathrm{~L}^{*} \mathrm{H}$ & $\mathbf{L H}^{*}$ & $\mathrm{LH}^{*} \mathrm{~L}$ & No accent \\
\hline f0-excursion of the rise in st & $1.86(0.51)$ & $0.99(16)$ & $5.84(2.16)$ & $2.91(0.92)$ & $3.17(1.03)$ & $1.44(0.74)$ \\
\hline fo-excursion of the fall in st & $1.05(0.91)$ & $2.54(0.95)$ & $3.58(3.96)$ & $0.78(1.59)$ & $2.34(1.03)$ & $1.90(1.55)$ \\
\hline Relative duration of nu (divided by verb duration) & $0.31(0.12)$ & $0.27(0.06)$ & $0.38(0.14)$ & $0.32(0.06)$ & $0.29(0.06)$ & $0.25(0.04)$ \\
\hline Alignment of the f0-maximum with respect to syllable onset in ms & $52.7(82.7)$ & $56.7(57.2)$ & $181.4(66.8)$ & $141.3(33.6)$ & $97.1(44.1)$ & $33.2(50.3)$ \\
\hline Alignment of the fo-minimum with respect to syllable onset in ms & $56.3(41.5)$ & $94.2(76.6)$ & $35.9(37.5)$ & $32.4(20.4)$ & $46.4(60.5)$ & $111.8(44.3)$ \\
\hline
\end{tabular}

\section{Table A4}

Intonation of $n u$ in the dominant word order from speakers in the variable word order group.

\begin{tabular}{lllclr}
\hline & $\mathrm{H}^{*}$ & $\mathrm{H}^{*} \mathrm{~L}$ & $\mathrm{~L}^{*} \mathrm{H}$ & $\mathrm{LH}^{*}$ & No accent \\
\hline LocationContrast & 4 & 1 & 17 & 6 & 3 \\
ObjectContrast & 9 & 2 & 5 & 3 & 12 \\
DoubleContrast & 7 & 4 & 8 & 2 & 6 \\
\hline
\end{tabular}

\section{Table A5}

Position of $n u$ in intonation phrase (IP) in non-dominant word order (e.g. Verplaats het boek nu naar vak 3 ).

\begin{tabular}{llll}
\hline & Break after nu & Break before nu & No break \\
\hline LocationContrast & 9 & 0 & 2 \\
ObjectContrast & 1 & 3 & 1 \\
DoubleContrast & 5 & 6 & 2 \\
\hline
\end{tabular}

\section{References}

Altman, H. (1976). Die Gradpartikeln im Deutschen. Untersuchungen zu iherer Syntax Semantik und Pragmatik. Tübingen: Niemeyer.

Baayen, R. H. (2008). Analyzing linguistic data. A practical introduction to statistics. Cambridge: Cambridge University Press.

Bartsch, R. (1972). Adverbialsemantik. Frankfurt: Athenäum Verlag.

Bayer, J. (1996). Directionality and logical form: On the scope of focusing particles and Wh-in-situ. Dordrecht: Kluwer.

Berger, F., Müller, A., Höhle, B., \& Weissenborn, J. (2007). German 4-year-olds' comprehension of sentences containing the focus particle auch (also): Evidence from eye-tracking. In $\mathrm{H}$. Caunt-Nulton, S. Kulatilake, \& I. Woo (Eds.), BUCLD 31: Proceedings of the 31st annual Boston University conference on language development, Vol. 1 (pp. 105-116). Somerville, MA: Cascadilla Press.

Bock, J. K. (1986). Syntactic persistence in language production. Cognitive Psychology, 18, 355-387.

Boersma, P., \& Weenink, D. (2009). Praat: Doing phonetics by computer (Version 5.1.25) [Computer program]. Retrieved January 20, 2010, from <http://www. praat.org/>.

Braun, B., \& Chen, A. (2008). Now move X into cell $Y$ : Intonation of 'now' in on-line reference resolution. In P. A. Barbosa, S. Madureira, \& C. Reis (Eds.), Proceedings of the fourth international conference on speech prosody (pp. 477-480) Campinas: Editora RG/CNPq.

Brazil, D. (1975). Discourse intonation 1. English language research. Birmingham: Birmingham University.

Büring, D., \& Hartmann, K. (2001). The syntax and semantics of focus-sensitive particles in German. Natural Language \&' Linguistic Theory, 19, 229-281.

Chen, A., den Os, E., \& de Ruiter, J. P. (2007). Pitch accent type matters for online processing of information status: Evidence from natural and synthetic speech. The Linguistic Review, 24, 317-344

Crain, S., Ni, W., \& Conway, L. (1994). Learning, parsing, and modularity. In C. Clifton, L. Frazier, \& K. Rayner (Eds.), Perspectives on sentence processin (pp. 443-467). Hillsdale, New Jersey: Lawrence Erlbaum Associates, Inc.
Cruttenden, A. (1997). Intonation (2nd ed.). Cambridge: Cambridge University Press. Dahan, D., Tanenhaus, M. K., \& Chambers, C. G. (2002). Accent and reference resolution in spoken-language comprehension. Journal of Memory and Language, 47, 292-314.

Dimroth, C., \& Watorek, M. (2000). The scope of additive particles in basic learner languages. Studies in Second Language Acquisition, 22, 307-336.

Field, A. (2009). Discovering statistics using SPSS. London (3rd ed.): Sage Publications.

Fodor, J. D. (2002). Prosodic disambiguation in silent reading. In M. Hirotani (Ed.) Proceedings of the North East Linguistic Society, Vol. 32). Amherst: GSLA University of Massachusetts.

Göbbel, E. (2003). On the relation between focus, prosody and word order in Romanian. In J Quer, J. Schroten, M. Scorretti, P. Sleeman, \& E. Verheugd (Eds.) Romance Languages and Linguistic Theory 2001: Selected papers from 'Going Romance 2001', Amsterdam, 6-8 December 2001. Amsterdam/Philadelphia: John Benjamins.

Grabe, E. (1998). Comparative intonational phonology: English and German. MPI Series in Psycholinguistics.

Grabe, E. (2004). Intonational variation in urban dialects of English spoken in the British Isles. In P. Gilles, \& J. Peters (Eds.), Regional variation in intonation (pp. 9-31). Tuebingen: Niemeyer.

Gussenhoven, C. (1984). On the grammar and semantics of sentence accents Dordrecht: Foris Publications.

Gussenhoven, C. (1988). Adequacy in intonation analysis: The case of Dutch. In $\mathrm{H}$. van der Hulst, \& N. Smith (Eds.), Autosegmental studies on pitch accent (pp. 95-121). Dordrecht: Foris.

Gussenhoven, C. (2005). Transcription of Dutch intonation. In S.-A. Jun (Ed.), Prosodic typology and transcription: A unified approach (pp. 118-145). Oxford: Oxford University Press.

Halliday, M. A. K., \& Hassan, R. (1976). Cohesion in English. Longman.

't Hart, J., Collier, R., \& Cohen, A. (1990). A perceptual study of intonation. Cambridge: Cambridge University Press.

Hirschberg, J., \& Litman, D. (1993). Empirical studies on the disambiguation of cue phrases. Computational Linguistics, 19, 501-530.

Keenan, E. L., \& Comrie, B. (1977). Noun phrase accessibility and universal grammar. Linguistic Inquiry, 8, 63-99.

Keller, F., \& Alexopoulou, T. (2001). Phonology competes with syntax: Experimental evidence for the interaction of word order and accent placement in the realization of information structure. Cognition, 79, 301-372.

Kim, S., \& Avelino, H. (2003). An intonational study of focus and word order variation in Mexican Spanish. In E. Herrera Z, \& P. Martín Butragueño (Eds.), La Tonía: Dimensiones Fonéticas y Fonológicas (pp. 357-374). Mexico City: Colegio de México.

König, E. (1994). Focus particles. In J. Jacobs, A. von Stechow, W. Sternefeld, \& T. Vennemann (Eds.). Syntax. Ein internationales Handbuch der zeitgenössischen Forschung (pp. 978-987). Berlin, New York: de Gruyter.

Krifka, M. (1991). Additive particles under stress. In Proceedings of the SALT 8 (pp. 111-128). Cornell: CLC Publications.

Ladd, D. R. (1996). Intonational phonology. Cambride: Cambridge University Press

Paterson, K. B., Liversedeg, S. P., White, D., Filik, R., \& Jaz, K. (2006). Children's interpretation of ambiguous focus in sentences with "only". Language Acquisition, 13, 253-284.

Pierrehumbert, J. B. (1981). Synthesizing intonation. Journal of Acoustical Society of America, 70, 985-995

Pierrehumbert, J., \& Hirschberg, J. (1990). The meaning of intonational contours in the interpretation of discourse. In P. R. Cohen, J. Morgan, \& M. E. Pollack (Eds.) Intentions in communication (pp. 271-311). Cambridge, MA: MIT Press.

Pinheiro, C., \& Bates, D. M. (2002). Mixed-effects models in S and S-PLUS. New York: Springer. 
Price, P. J., Ostendorf, M., Shattuck-Hufnagel, S., \& Fong, C. (1991). The use of prosody in syntactic disambiguation. Journal of the Acoustical Society of America, 90(6), 2956-2970.

Prince, E. (1978). A comparison of WH-clefts and it-clefts in discourse. Language, 54, 883-906.

Reis, M., \& Rosengren, I. (1997). A modular approach to the grammar of additive particles: The case of German auch. Journal of Semantics, 14, 237-309.

Rooth, M. (1992). A theory of focus interpretation. Natural Language Semantics, 1 75-116.

Shiffrin, D. (1987). Discourse markers. Cambridge: Cambridge University Press.

Snedeker, J., \& Trueswell, J. (2002). Using prosody to avoid ambiguity: Effects of speaker awareness and referential context. Journal of Memory and Language, 48 , 103-130.

Speer, S. R., Kjelgaard, M. M., \& Dobroth, K. M. (1996). The influence of prosodic structure on the resolution of temporary syntactic closure ambiguity. Joumal of Psycholinguistic Research, 25, 247-268.
Speer, S. R., Warren, P., \& Schafer, A. (2003). Intonation and sentence processing. In M. J. Solé, D. Recasens, \& J. Romero (Eds.). Proceedings of the 15th international congress of phonetic sciences (pp. 95-105). Barcelona.

Steedman, M. (2000). Information structure and the syntax-phonology interface. Linguistic Inquiry, 31, 649-689.

Swerts, M. (2007). Contrast and accent in Dutch and Romanian. Journal of Phonetics, 35, 380-397.

Swerts, M., \& van Wijk, C. (2005). Prosodic, lexico-syntactic and regional influences on word order in Dutch verbal endgroups. Journal of Phonetics, 33, 243-262.

Terken, J., \& Hirschberg, J. (1994). Deaccentuation of words representing 'Given' information: Effects of persistence of grammatical role and surface position. Language and Speech, 37, 125-145.

Vallduví, E., \& Engdahl, E. (1996). The linguistic realisation of information packaging. Linguistics, 34, 459-519.

Zubizarreta, M. L. (1998). Prosody, focus, and word order. Cambridge, MA: MIT Press. 